\section{Arctic: speed of methane release}

Gail Whiteman and colleagues suggest that the opening up of the Arctic Ocean could bring more economic costs than benefits, owing to climatic effects resulting from a sudden release of 50 gigatonnes of methane from the area (Nature 499, 401-403; 2013). However, our literature review of the impact of sea-ice decline on Arctic greenhouse-gas exchange indicates that methane release is likely to be more gradual because of a slow rate of heat penetration into the subsea permafrost (see F. J. W. Parmentier et al. Nature Clim. Change 3, 195-202; 2013). We therefore believe that the proposed scenario is unlikely.

Although the Arctic Ocean represents a substantial source of methane, there are still many unknowns. Any research that assumes a large increase in emissions from that region should therefore include ample discussion of the uncertainties relating to this source.

Frans-Jan W. Parmentier, Torben R. Christensen Lund University, Sweden. frans-jan.parmentier@nateko.lu.se

\section{Arctic: uncertainties in methane link}

We disagree with Gail Whiteman and colleagues that there is "likely" to be a large and sudden release of methane from the East Siberian Arctic Shelf (Nature 499, 401-403; 2013).

Such an event would require an almost 1,000-fold regional increase in methane emissions from thawing permafrost, which would be inconsistent with geological evidence: although the concentration of atmospheric methane rose in response to abrupt warming during recent deglaciations, isotopic methane measurements do not indicate that the gas came from marine gas hydrates during these periods (H. Fischer et al. Nature 452,
864-867; 2008).

Sea-floor temperatures

determine the stability of methane hydrate reservoirs. To our knowledge, there is no evidence that these temperatures have changed significantly in the past few decades, or that a sudden change is imminent.

Although elevated methane concentrations have been observed in water and the atmosphere above the East Siberian Arctic Shelf, it is not clear whether these have been caused by recent warming or by natural processes linked to glacial-interglacial changes (V. V. Petrenko et al. Science 329, 1146-1147; 2010). The global increase in methane recorded in the past few years does not seem to have been caused by enhanced Arctic emissions.

We welcome studies that quantify the economic impact of global warming, but they need to be accompanied by a realistic assessment of the uncertainties.

Dirk Notz, Victor Brovkin Max Planck Institute for Meteorology, Hamburg, Germany.

dirk.notz@zmaw.de

Martin Heimann Max Planck Institute for Biogeochemistry, Jena, Germany.

Gail Whiteman, Chris Hope and Peter Wadhams respond: Since 2005, accelerating sea-ice retreat in the Arctic has exposed the sea bed to much warmer conditions than those considered in earlier studies that anticipated a slow release of methane. Summer water temperatures off Siberia now climb to several degrees above $0^{\circ} \mathrm{C}$ (see, for example, N. R. Bates et al. Biogeosciences 10, 5281-5309; 2013), causing the upper layers of offshore permafrost to melt more rapidly than they did a decade ago.

We have rerun our model with the same total quantity of emitted methane, but released over 50 or 75 years rather than 10 years. The results show no reduction in the total cost to society - in fact, the discounted costs over time would be larger.

\section{Arctic: warming impact is uneven}

We support the call for more rigorous integrated modelling of the costs and benefits of Arctic warming (G. Whiteman et al. Nature 499, 401-403; 2013).

Such models should examine the distribution of these costs and benefits within, as well as between, countries.

Melting permafrost, as Whiteman et al. show, gives rise to costly methane emissions. In addition, it damages the infrastructure needed for shipping and transportation, and for gas, oil and mineral mining, at high northern latitudes; this is because previously solid ground loses its structural integrity.

The Madrid-based humanitarian organization DARA expects the cost of this damage in the Arctic to reach US $\$ 80$ billion annually by 2030 (see go.nature.com/vnlzax). These losses will be unevenly distributed, with more than 90\% likely to occur in Russia. The benefits from naturalresource extraction will also vary significantly between countries.

Indigenous peoples in the far north, who are already marginalized, will be subjected to further economic hardship and deteriorating conditions for their traditional hunting and land-use practices.

We believe that the uneven distribution of costs and benefits of Arctic warming calls for a new approach to governance in the region. This should ensure equitable compensation and support for those affected most. Janis Hoberg, Francisco Ascui University of Edinburgh, UK. janis.hoberg@gmail.com

\section{Brain stimulation has a long history}

Self-administered transcranial electrical stimulation (TES) is not new (see Nature 498, 271-272; 2013). Between the 1740s and 1930s, there was widespread and unregulated commercial availability of TES machines for private and domestic use (see, for example, I. R. Morus in Frankenstein's Children, Princeton University Press; 1998).

During Victorian and Edwardian times, TES machines that dispensed static, frictional, faradic or battery electrical current could be bought everywhere. Some physicians, therapists and patients claimed that TES could generate feelings of euphoria and even improve mental performance.

Physicians of the period recommended that currents of no more than 5-10 milliamps should be applied to the head because of the risks of burning and shock, although many users chose to experiment. Side effects included headaches, flashes of light, dizziness and nausea, especially when connections were imperfect or broken.

The consequences could be even more serious. The Dutch physician Jan Ingenhousz knocked himself unconscious when performing electrical experiments in 1783, and Benjamin Franklin suffered retrograde amnesia after accidentally administering an electric shock to his head.

As today, some medical practitioners of the time believed the benefits of TES to be exaggerated.

Roi Cohen Kadosh Department of Experimental Psychology, University of Oxford, UK. Paul Elliott School of Humanities, University of Derby, UK.

p.elliott@derby.ac.uk

CONTRIBUTIONS

Correspondence may be submitted to correspondence@nature. com after consulting the guidelines at http:// go.nature.com/cmchno. Alternatively, readers may comment online: www. nature.com/nature. 